Research Article

\title{
Functionalized Waterborne Polyurethane-Based Graphite-Reinforced Composites
}

\author{
Nur Munirah Abdullah $\mathbb{D}^{1},{ }^{1}$ Anika Zafiah Mohd Rus $\mathbb{D}^{1},{ }^{1}$ and M. F. L. Abdullah $\mathbb{D}^{2}$ \\ ${ }^{1}$ Sustainable Polymer Engineering, Advanced Manufacturing and Materials Center (SPEN-AMMC), \\ Faculty of Mechanical and Manufacturing, Universiti Tun Hussein Onn Malaysia, 86400 Parit Raja, \\ Batu Pahat, Johor, Malaysia \\ ${ }^{2}$ Department of Communication Engineering, Faculty of Electrical and Electronic Engineering, \\ Universiti Tun Hussein Onn Malaysia, 86400 Parit Raja, Batu Pahat, Johor, Malaysia
}

Correspondence should be addressed to Anika Zafiah Mohd Rus; zafiah@uthm.edu.my

Received 24 January 2019; Accepted 1 April 2019; Published 4 June 2019

Academic Editor: Massimiliano Barletta

Copyright (C) 2019 Nur Munirah Abdullah et al. This is an open access article distributed under the Creative Commons Attribution License, which permits unrestricted use, distribution, and reproduction in any medium, provided the original work is properly cited.

\begin{abstract}
The synthesis and characterization of waterborne polyurethane-based oxidized graphite- (WPUG-) reinforced composites is disclosed. The morphology-structure relations of WPUG composites are studied using field emission scanning electron microscopy (FESEM) and Fourier transform infrared (FTIR) spectroscopy. Prior to this, it is confirmed that, in the WPUG composites, the graphite particles containing functional groups such as hydroxyl and carboxylic groups are randomly distributed and attributed to the formation of interconnected interface within the polymeric composites. This promotes enhancement in modulus and tensile strength up to $\sim 440 \%$ and $\sim 100 \%$, respectively. Significantly, these results were correlated with viscoelastic properties in which the composites show positive response to graphite addition. Further studies in optical properties consequently attribute decreasing values in optical energy band gap $\left(E_{\mathrm{g}}\right)$ which afterwards took the leads to electrical conductivity $(\sigma)$. Aptly, the composites $\mathrm{WPUG}_{20}, \mathrm{WPUG}_{25}$, and WPUG 30 were found to possess favorable electrical conductivity through the two-point probe method. This revealed the improvement in electrical properties with promising potential as alternative petroleum-based composites to generate energy from the renewable resources and also apply greener ways for energy consumption.
\end{abstract}

\section{Introduction}

Demand and necessity for sustainability, cost reductions, environmental issues, and competitive properties are the bases for the development of new class polymer-based biomaterials. The utilization of raw biomaterials should meet the $7^{\text {th }}$ principle of 12 Principles of Green Chemistry [1]. Appropriately, only by applying all these principles, one can achieve a truly sustainable process. Because of the universal availability, inherent biodegradability, and low price of vegetable oils, they have now become an area of intensive interest for both academic and industrial research as a chemical platform for polymeric materials. Particular attention has been paid to investigate the suitability of vegetable oil-based polymers (VOBPs) as future biomaterials. Polymers from renewable resources, either insulating or conducting, hold a key of interest based on their chain fundamentals. Therefore, in order to maximize their usage, modification through addition of specific additives as filler is needed. Inspired by the findings in [2], carbon-based composites, such as carbon black (CB) [3, 4], carbon nanotubes [5-7], activated carbon $[8,9]$, and graphene $[10,11]$, have attracted attention due to their excellent mechanical, thermal, and electrical properties which make them excellent candidates for multidisciplinary area.

The homogeneous dispersion of nanotubes in polymer matrix, without terminating their reliability, has been considered as a vital factor for efficient utilization of these nanofillers in nanocomposite applications. The interconnected interface of the composites is dependent on the 
intensity of signals such as $\mathrm{C}-\mathrm{O}$ or $\mathrm{N}-\mathrm{H}$ due to the changing matrix-filler interactions $[12,13]$. Most prominent characteristics that are affected due to reinforcement are the mechanical properties of the polymer matrix. Previously, Cai et al. had fabricated an impregnation of epoxy resin with porous graphene nanoplatelet $(\mathrm{GnP})$ paper composites with one-layer $(0.15 \mathrm{~mm}$ thick) and 15-layer (5.43 $\mathrm{mm}$ thick) graphene composites [14]. The results demonstrated that the 15-layer graphene composite had better material properties than the 1-layer graphene composites through both tensile and dynamic mechanical analysis (DMA) tests. By itself, the storage modulus of a 15-layer graphene composite was $170 \%$ higher than that of neat epoxy, while the transverse surface of the composite exhibited a higher elastic modulus but lower hardness than the top surface. Furthermore, other researchers found that by the addition of $2 \mathrm{wt} . \%$ of multiwalled carbon nanotubes (MWCNTs) into polyurethane, the tensile elastic modulus increased up to $100 \%$, whilst the storage modulus and the glass transition temperature, $T_{\mathrm{g}}$, through DMA are not highly affected by the addition [15]. However, Strankowski and his college recorded the highest tensile strength at $0.5 \mathrm{wt} . \%$ of reduced graphene oxide (RGO) in the polyurethane matrix, $2.95 \mathrm{kPa}$ with $457 \%$ of elongation at break [16]. It is also noted that both hardness and the storage modulus were improved, which causes shifted values in $T_{\mathrm{g}}$.

On the contrary, the optical measurements constitute the most important means of defining the optically induced transitions, band gap energy, and band structure of the materials $[17,18]$. Zhou and his colleagues prepared high thermal conducting expandable graphite-filled polyamide 6 (LTEG-PA6) composites via low temperature in situ exfoliation process [19]. The thermal conductivity of the LTEGPA6 composite reached $21.05 \mathrm{Wm}^{-1} \cdot \mathrm{K}^{-1}$ at its maximum filler loading of $60 \mathrm{wt} . \%$ whereby this conductivity was approximately 72 times higher than that of the virgin PA6. Other researchers described bipolar plates consisting of synthetic graphite and milled carbon fibers as conductive filler and epoxy as a polymer matrix [20]. Likewise, the composite containing 2 wt.\% carbon fiber (CF) with 80 wt.\% filler loading obtained the highest electrical conductivity $50.34 \mathrm{~S} /$ $\mathrm{cm}$ for the through-plane conductivity and $69.8 \mathrm{~S} / \mathrm{cm}$ for the in-plane conductivity. Interestingly, these values are $30 \%$ greater than the electrical conductivity values of a typical graphite/epoxy composite with 80 wt.\% filler loading, which are $53 \mathrm{~S} / \mathrm{cm}$ for the in-plane conductivity and $40 \mathrm{~S} / \mathrm{cm}$ for the through-plane conductivity. Moreover, it was found the critical electrical percolation threshold for the ternary conductive polymer composites decreased more than 8 times lower than the single phase systems [21].

In this research, waterborne polyurethane-based graphite-reinforced composites were proposed as "green" conductive polymer composites. The influence of the graphite particles towards the waterborne polyurethane properties was investigated. Strong interconnected particles between graphite particles and waterborne polyurethane matrix are evident to physical, mechanical, optical energy band gap, and electrical properties of the WPUG composites. The improvement in their properties were marginal; however, the positive responses of the composites especially towards optical energy band gap of waterborne polyurethane and its consequent composites with addition of graphite particles have not been disclosed elsewhere. Due to this, the basic properties of segmented waterborne polyurethane composites such as their functional fingerprints, mechanical, the phenomena underlying their conductivity, and the ways to tailor their properties are discussed.

\section{Experimental}

2.1. Materials. The required main raw materials for waterborne polyurethane-based graphite-reinforced (WPUG) composite preparation are graphite flakes, waterborne monourethane and cross-linker, and methylene diphenyl diisocyanate (MDI). For this, the graphite flakes of irregular shapes with an average size of $\sim 20 \mu \mathrm{m}$ (Product No. 282863) used is supplied by May \& Baker Ltd., England, whist the MDI is from ALDRICH (CAS number 101-68-8). Virgin cooking oil (VCO) was used as waterborne monourethane preparation, in addition to all other chemicals and reagents for the acid-catalyst preparation, and is from SYSTERM ChemAR.

2.2. Preparation of Graphite. In this manner, the flake graphite mixture (with sulfuric acid, $\mathrm{H}_{2} \mathrm{SO}_{4}$ ) was placed into a flask in the ultrasonic cleaning bath at room temperature and sonicated for 60 minutes. After the sonication, the presence of yellow solution indicated a high oxidation of graphite. Furthermore, the precipitate of graphite mixture was collected and washed to neutrality with water (confirmed via $\mathrm{pH}$ paper), which later being dehydrated and dried in an oven. This method has been adopted from the previous work [22-24], whereas the chemical equation of the prepared graphite is illustrated in the following equation:

$$
\begin{aligned}
& n \text { (graphite) }+n \mathrm{H}_{2} \mathrm{SO}_{4}+\frac{n}{2}[\mathrm{O}] \\
& \left.\longrightarrow n \text { [graphite } \cdot \mathrm{HSO}_{4}\right]+\frac{n}{2 \mathrm{H}_{2} \mathrm{O}}
\end{aligned}
$$

where $\mathrm{O}$ is the oxidant, graphite. $\mathrm{HSO}_{4}$ stands for the graphite intercalation compounds (GICs), and the stage number $n$ designates the number of graphene layers that separate the adjacent intercalate layers. These results suggest a morphological view and the oxygen-containing functional groups (carboxylic and hydroxyl) formation verified by the Fourier transform infrared spectroscopy (FTIR) analysis as shown in Figure 1. According to the FTIR spectra, the present graphite particles show multiple signs of oxygenderived species. These functional groups (carboxylic and hydroxyl) in graphite would enhance the interconnected particles within the waterborne polymer matrix $[26,27]$.

2.3. Preparation of Waterborne Polyurethane. The starting waterborne monourethane conversion begins with several steps using virgin cooking oil (VCO) which has been chemically manipulated at laboratory scale using less than 1 


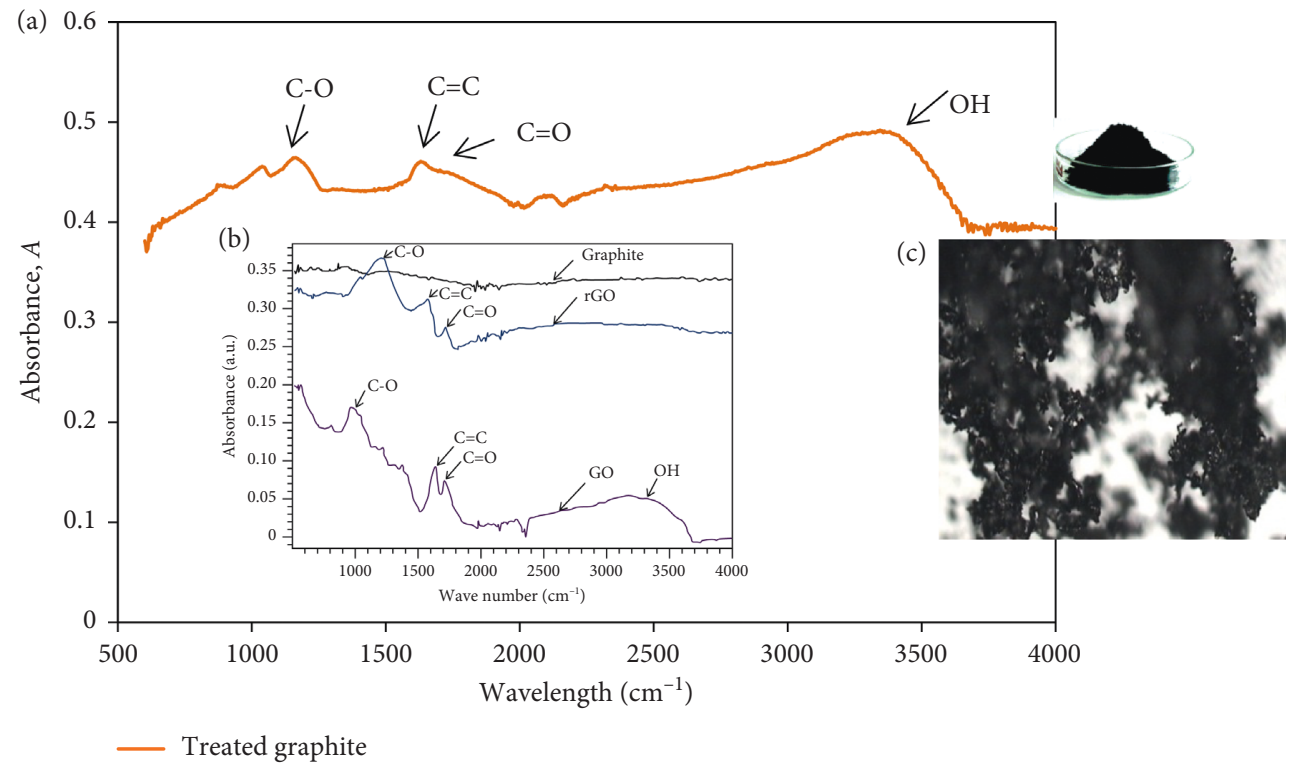

FIGURE 1: The structure of the present graphite through (a) FTIR of 500-4000 $\mathrm{cm}^{-1}$ region with comparative (b) FTIR from previous research $[25]$ and (c) the optical morphology view at 50x of magnifications.

$\mathrm{L} /$ run of cooking oil as asserted in the Intellectual Property Protection PI 201000633; 2010/PT/TMI/PTA1.81/APP/ 0479/PCG in December 2010, "Versatile Polymer Thin Films from Renewable Resources." The process was performed in two steps: the first step is the preparation of inhouse catalyst to generate the epoxides from the unsaturated fatty compounds and the second step is the acid-catalysed ring opening of the epoxides to form polyols. Moreover, for the in-house catalyst preparation, $0.6 \mathrm{~mL}$ of distilled water and $1.26 \mathrm{~mL}$ hydrogen peroxide $(30 \% \mathrm{w} / \mathrm{w})$ were added and the solution was heated at $50^{\circ} \mathrm{C}$ and stirred (for about 30 minutes). Subsequently, the solution was let to sit at room temperature, and later on, a concentration of aqueous orthophosphoric acid (90 mg, 85\% w/w) (1.2 mL) was poured in. Virgin cooking oil of $30 \mathrm{gm}$ in weight was heated at $50^{\circ} \mathrm{C}$, and the in-house catalyst prepared earlier was added, followed by $50 \mathrm{~mL}$ of water. Furthermore, orthophosphoric acid $(15 \mathrm{gm}, 85 \% \mathrm{w} / \mathrm{w})$ and hydrogen peroxide $(18 \mathrm{~mL}, 30 \% \mathrm{w} / \mathrm{w})$ were added dropwise into the mixture. Next, the mixture was heated up to $90^{\circ} \mathrm{C}$ and stirred for 6 hours until the double layers of mixture were observable, and this noticeably yielded the waterborne polyurethane.

\subsection{Preparation of Waterborne Polyurethane-Based Graphite-} Reinforced Composites. The waterborne monourethane from the previous section was admixed with methylene diphenyl diisocyanate (MDI) and solvent to form waterborne polyurethane based on the ratio in Table 1 . The mixture was stirred using a mechanical stirrer at the optimum condition of $50^{\circ} \mathrm{C}$ until a compound with high viscosity was achieved [28, 29]. The mixture was then been spread onto a Teflon sheet through the slip casting method and left to cure at ambient temperature for at least 6 hours so as to ensure a complete removal of solvent traces. Soon as it dried, the resulting films were peeled off. Micrometer and optical microscope images are employed to measure the thickness of the sample at particular points ranging $\sim 0.1 \mathrm{~mm}$ in accordance with ASTM D1005-95. Likewise, the above fabrication steps of waterborne polyurethane composites with different ratios of graphite are shown in Figure 2.

2.5. Characterization. The morphology-structure of cross section and surface images were observed through the dield emission scanning electron microscopy (FESEM) model JEOL JSM-7600F. The prepared samples of dimension $\sim 2 \mathrm{~mm} * 2 \mathrm{~mm} * 0.1 \mathrm{~mm}$ were firstly coated with a thin layer of gold $(\mathrm{Au})$ by using a sputter coating on a specimen holder and further imaged by FESEM at $15 \mathrm{kV}$.

Fourier transform infrared (FTIR) is one of the most powerful tools for identifying the types of chemical bonds (functional groups) when being analyzed by infrared light. In this application, PerkinElmer spectrometer (Spectrum 100) Universal ATR (attenuated total reflection) was used. The samples were cut into small pieces $(10 \times 10 \times 0.1 \mathrm{~mm})$ and tested in the range of 600 to $4000 \mathrm{~cm}^{-1}$, collecting 32 scans with $4 \mathrm{~cm}^{-1}$ resolution.

The tensile test was measured by using the universal testing machine (LLOYD Instruments LR30K) to obtain tensile strength, modulus, and elongation at break of a material according to ASTM D882. The tensile machine with a load range of $20 \mathrm{~N}$, cross head speed of $500 \mathrm{~mm} \cdot \mathrm{min}^{-1}$, gauge length of $100 \mathrm{~mm}$, and efficiency within $\pm 1 \%$ was implied. A minimum of prepared five samples were analyzed at room temperature in order to obtain an average result.

Dynamic mechanical analysis (DMA) Q800 was used to determine the viscoelastic properties of the waterborne polyurethane-based graphite-reinforced composites. Practically, all samples were cut to range between 5 and $6.5 \mathrm{~mm}$ in width and $20-30 \mathrm{~mm}$ in length according to the measurement board for tension film clamp test fixture. The 
TABLE 1: Sample preparation of waterborne polyurethane composites with different ratios of graphite weight loading (\%).

\begin{tabular}{llcc}
\hline Sample & Components & Weight ratio & Weight percent (wt/wt.\%) \\
\hline WPUG $_{0}$ & Monomer/MDI/graphite & $2 / 1 / 0$ & 0 \\
WPUG $_{5}$ & Monomer/MDI/graphite & $2 / 1 / 0.1$ & 5 \\
WPUG $_{10}$ & Monomer/MDI/graphite & $2 / 1 / 0.2$ & 10 \\
MPUG $_{15}$ & Monomer/MDI/graphite & $2 / 1 / 0.3$ & 15 \\
MUUG $_{20}$ & Monomer/MDI/graphite & $2 / 1 / 0.4$ & 20 \\
WPUG $_{25}$ & Monomer/MDI/graphite & $2 / 1 / 0.5$ & 25 \\
PPUG $_{30}$ & & $2 / 1 / 0.6$ & 30 \\
\hline
\end{tabular}
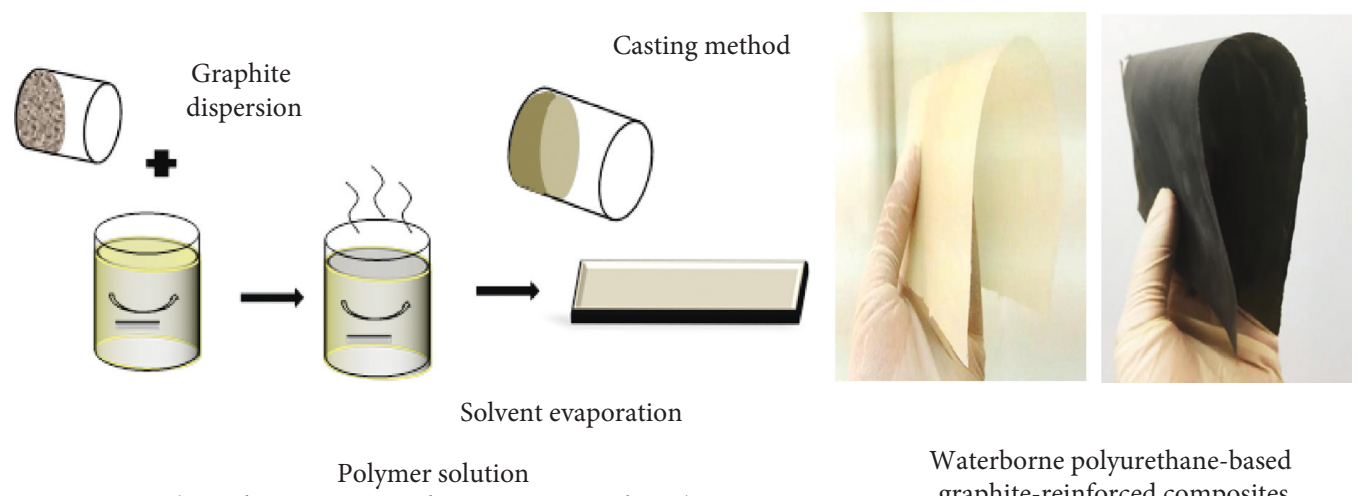

(waterborne monourethane + MDI + toluene)

Waterborne polyurethane-based graphite-reinforced composites

FIGURE 2: Schematic diagram of waterborne polyurethane-based graphite-reinforced composites.

thickness of each sample was recorded. The film tension test was also conducted with initial room temperature at $30^{\circ} \mathrm{C}$ and heated at $3^{\circ} \mathrm{C} / \mathrm{min}$ up to $120^{\circ} \mathrm{C}$. The samples were tested with a single frequency oscillation of $1 \mathrm{~Hz}$ and amplitude of $20 \mu \mathrm{m}$ using a dynamic force. Further storage modulus for each testing was calculated as a function of increasing temperature using thermal analysis software including the DMA apparatus. Moreover, the cross-link density $\left(V_{\mathrm{e}}\right)$ of a cross-linked polymer can be determined from the rubbery modulus by using the following equation, based on the rubber elasticity:

$$
E^{\prime}=3 V_{\mathrm{e}} R T
$$

where $E^{\prime}$ is the storage modulus in the rubbery plateau above $T_{\mathrm{g}}\left(\right.$ ca. $\left.T_{\mathrm{g}} \pm 10^{\circ} \mathrm{C}=T\right), \quad R$ is the gas constant $\left(8.314 \mathrm{JK}^{-1} \cdot \mathrm{mol}^{-1}\right)$, and $T$ is the temperature in Kelvin.

Following this, the absorbance or reflectance spectroscopy was referred by using the Shimadzu UV-1800 UV Spectrophotometer over the wavelength range of 200$600 \mathrm{~nm}$ with a $1 \mathrm{~nm}$ resolution according to ASTM E275-08.

The two-point probe method measures the resistance between two electrodes. As in this work, the current-voltage characteristic measurements of the WPUG composites were carried out using the Keithley 6517A electrometer and carefully measured the width $(w)$, electrode distance $(L)$, and film thickness $(t)$. Incoherent from the slopes of the current-voltage $(\mathrm{I}-\mathrm{V})$ characteristics, resistance $(R)$ was determined. Therefore, electrical resistivity, $\rho$, and conductivity, $\sigma$, were calculated based on the following equation:

$$
\rho=\sigma-1 R t\left(\frac{w}{L}\right)
$$

\section{Results and Discussion}

3.1. Morphology and Structural Study. Surface morphology views of waterborne polyurethane-based graphite-reinforced composites through FESEM are shown in Figure 3. The pure waterborne polyurethane exhibits smooth surface (above) without any particles and pores, which is also observed from cross-sectional image (below). However, when graphite particles were incorporated into waterborne polyurethane, the composites exhibits rough surface images. As the concentration increases, more graphite particles were aggregated and form bigger agglomeration. It is said that the graphite is not a single-layer structure but rather consists of a few layers or stacks of graphite flakes [30]. Later, formations of graphite pathways in the polymer host are revealed. The high content of graphite will form a number of hopping channels that are considered as alternative paths for electrical transportations [6], thus driving electron conductive properties of the graphite. This phenomenon will be discussed in the following section. Regardless of graphite particles randomly distributed and randomly oriented, the morphological structure of WPUG composites visibly remarks a good dispersion state of graphite within the waterborne polyurethane matrix and a strong interaction between graphite filler with the polymer host. This improved interfacial bonding in the composites could be ascribed to two effects: (i) strong $\pi-\pi$ interaction between the sheet and the backbone of the polymer chains and (ii) the compatibility and covalent reaction between the epoxy matrix and the polymer chain grafted on the graphite particles [31-33].

The addition of graphite particles not only contributes to dense morphological structure of the composites but also 

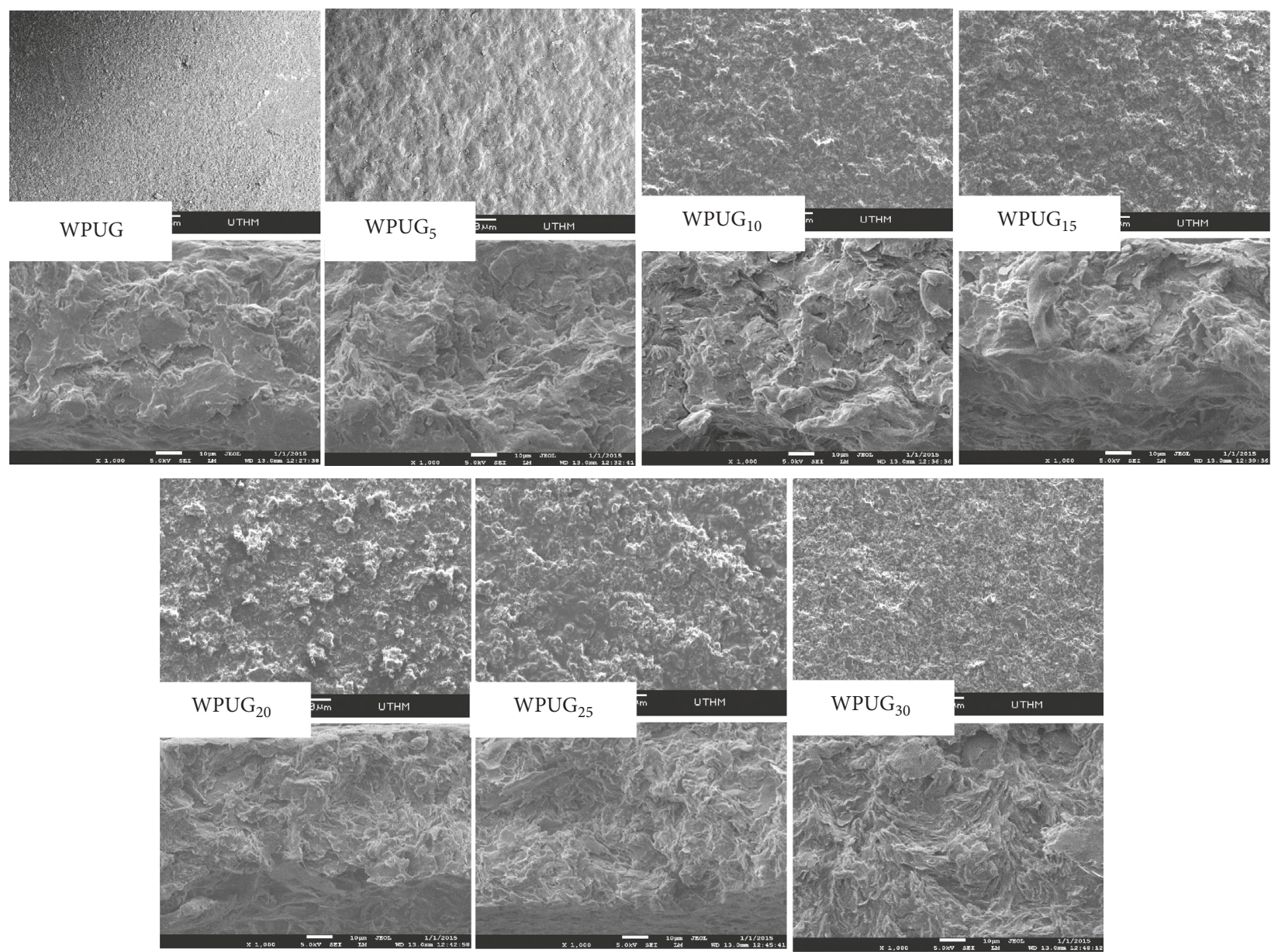

FIGURE 3: FESEM morphology of waterborne polyurethane-based graphite-reinforced composites.

increases the density as well as decreases the moisture content of the system as shown in Figure 4.

The results demonstrate that the composite density is in the range of $0.905-0.935 \mathrm{~g} / \mathrm{cm}^{3}$, where it is still lightweight, less dense than water $\left(1 \mathrm{~g} / \mathrm{cm}^{3}\right)$. Meanwhile, the decreasing of moisture content at a range of $0.44-0.39 \%$ is needed as the WPUG composites predicted to conduct electricity. The low moisture content at higher graphite particle loading that is more stagnant hints that the internal friction of the composites was reduced [34] compared to its counterpart.

Most apparent bands in pure waterborne polyurethane also occur in modified waterborne polyurethane composites. It confirms that the achieved waterborne polyurethanebased graphite-reinforced composite system has their characteristic signals from the existing chemical groups and additives as shown in Figure 5. Most important fact of the composites is the lack of isocyanate band at $2275 \mathrm{~cm}^{-1}$, which indicate all NCO groups from MDI have been successfully bonded together to form urethane groups containing $\mathrm{N}-\mathrm{H}\left(3340 \mathrm{~cm}^{-1}\right), \mathrm{C}=\mathrm{O}\left(1730 \mathrm{~cm}^{-1}\right)$, and C-O-C $\left(1140-1180 \mathrm{~cm}^{-1}\right)$ with C-N $\left(1240 \mathrm{~cm}^{-1}\right)$ signals. Formation of ester and ether as strong peaks at $1100-1200 \mathrm{~cm}^{-1}$ was observed. The ester group was located along with the fatty acid chains and urethane, in contrast with the ether group which produced in the vicinity of the side chain [35].

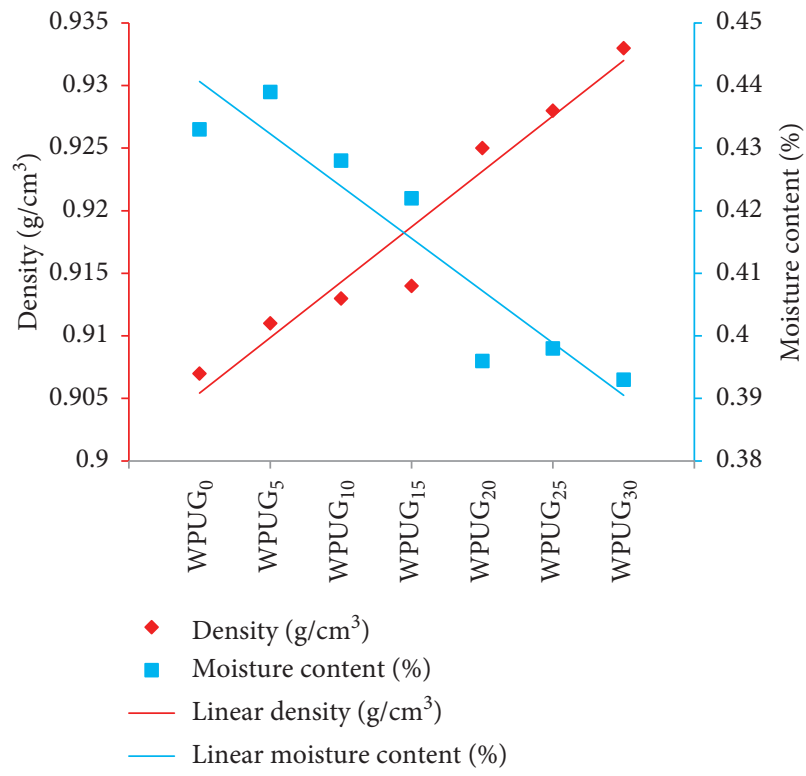

FIgURE 4: Physical properties of waterborne polyurethane-based graphite-reinforced composites.

This ether group specifically known as the methoxy group, which was based from methanol, was used during the ringopening step in producing waterborne monourethane. 


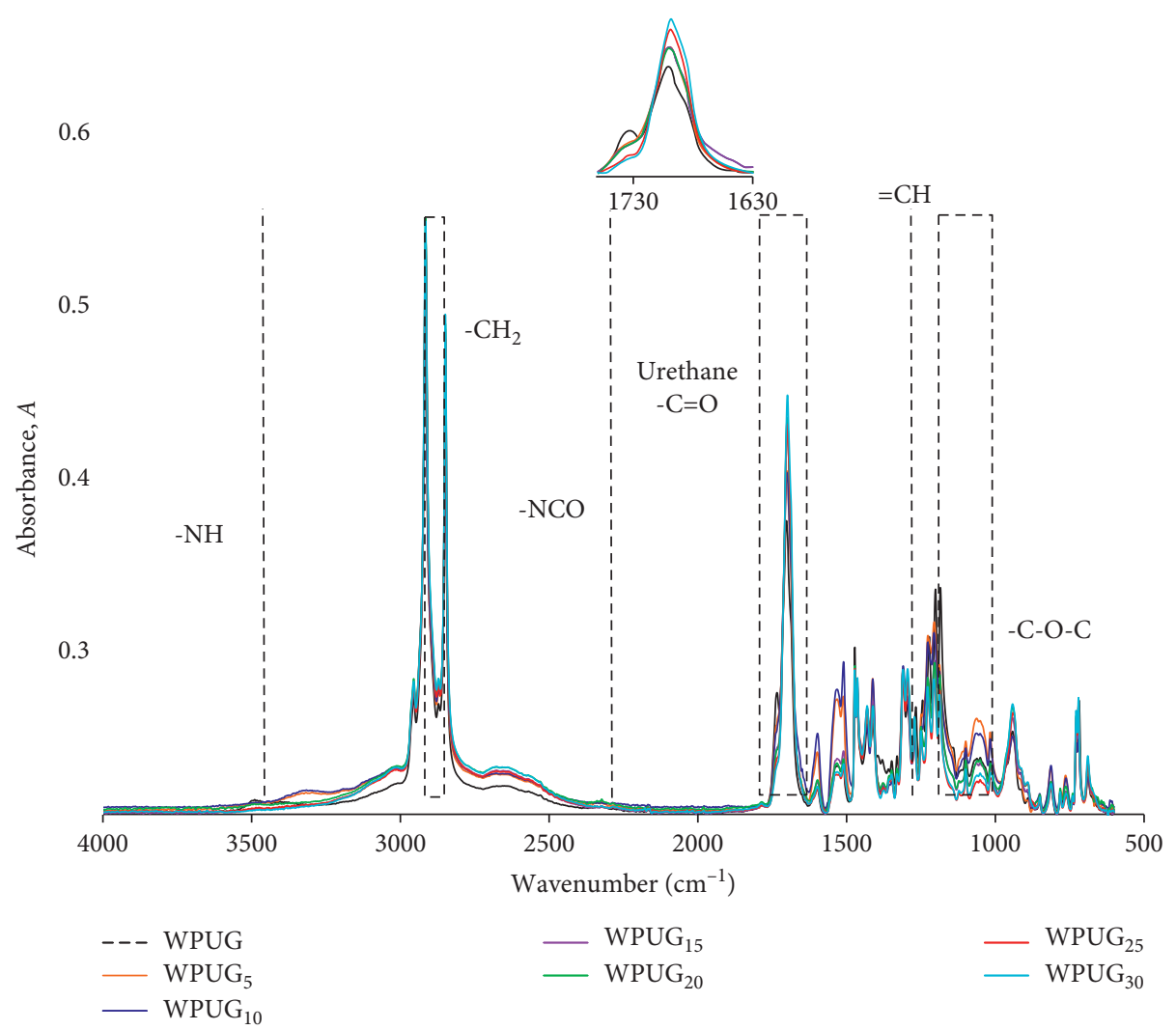

FIGURE 5: FTIR spectra at the region of $4000-500 \mathrm{~cm}^{-1}$ of waterborne polyurethane-based graphite-reinforced composites.

Another peak that is observable in the spectra is the stretching vibration of the hydroxyl group at $3200 \mathrm{~cm}^{-1}$, which is from water molecule due to hygroscopicity of graphite, graphite oxide (GO), and treated graphite [36]. In addition, the casting mixtures were solvent free and produced waterborne polyurethane sheets that reflected the origin color of the polyol/waterborne monourethane. In addition, this waterborne polyurethane-based graphite-reinforced composite is well known for its two phase microstructure containing soft and hard segments arranged alternately. Thus, to further investigate the phase existing in the waterborne polyurethane-based graphite-reinforced composites, one needs to determine the consequent degree of phase separation (DPS). It is described that the phase separation is the sharing of a hard segment with bounded hydrogen bonds. The hydrogen bonding in the waterborne polyurethane-based graphite-reinforced composites is present in the IR spectra of the three functional groups: $\mathrm{N}-\mathrm{H}\left(3500-3200 \mathrm{~cm}^{-1}\right), \mathrm{C}=\mathrm{O}$ $\left(1800-1600 \mathrm{~cm}^{-1}\right)$, and $\mathrm{C}-\mathrm{O}-\mathrm{C}\left(1200-1000 \mathrm{~cm}^{-1}\right)$. In these three functional groups, $\mathrm{N}-\mathrm{H}$ supplies the proton, whilst $\mathrm{C}=\mathrm{O}$ and $\mathrm{C}-\mathrm{O}-\mathrm{C}$ supply the lone-pair electron.

As a result, two types of hydrogen bonds, $\mathrm{N}-\mathrm{H} / \mathrm{O}-\mathrm{C}$ and $\mathrm{N}-\mathrm{H} / \mathrm{O}=\mathrm{C}$, could be formed in the composites. Theoretically, the hydrogen bond of $\mathrm{N}-\mathrm{H} / \mathrm{O}=\mathrm{C}$ mostly exists in the hard segments, contrary to the free carbonyl groups which are present in the soft segments. Nevertheless, the degree of phase separation in the composites could be related to the relative intensity of these two types of $\mathrm{C}=\mathrm{O}$ in the FTIR spectra. The degree of phase separation (DPS) [35-37] can be calculated by using the following equation:

$$
\mathrm{DPS}=\frac{R}{(R+1)},
$$

where $R$ represents the carbonyl hydrogen bonding index $\left(A_{1701} / A_{1736}\right)$. The DPS caused by each of the hydrogen bonds are favored in all the prepared PG samples, where $\mathrm{WPUG}_{0}=70.9 \%, \quad \mathrm{WPUG}_{5}=79.4 \%, \quad \mathrm{WPUG}_{10}=80.6 \%$, $\mathrm{WPUG}_{15}=85.9 \%, \mathrm{WPUG}_{20}=68.1 \%, \mathrm{WPUG}_{25}=87.6 \%$, and $\mathrm{WPUG}_{30}=89.7 \%$. Based on the previous work, Vegabaudrit and his collogues [38] proposed that the sample with the highest DPS ratio, which has the highest hard segment content, thus promote highest values in the storage and loss modules and an increase in temperature and modulus of softening due to mixture of phases. The result clearly shows that $R$ and DPS values increase with the relative weight percent of graphite particles in the composite. These mean that the main interactions are established in waterborne polyurethane with graphite particles corresponding to soft segment-soft segment, which affects the association-dissociation equilibrium of hydrogen bonding.

3.2. Tensile Behavior. The mechanical behavior through the tensile test of waterborne polyurethane-based graphitereinforced composites is highly corresponding to the materials intrinsic properties, quantity, degree of dispersion, polymer matrix properties, and the interaction between graphite content and polymer matrix. Such properties such as tensile strength and of waterborne polyurethane matrix are predicted to be improved with the addition of graphite 
particles. As shown, Figure 6 demonstrates the elastic modulus, tensile strength, and elongation at break properties of waterborne polyurethane-based graphite-reinforced composites with respect to carbonyl hydrogen index, $R$, and subsequent DPS. The phase separation in segmented polymer is interpreted as the incompatibility between the soft and the hard segments which tailors the mechanical properties of the composites.

Clearly, both elastic modulus (Figure 6(a)) and the tensile strength (Figure 6(b)) of the waterborne polyurethane-based graphite-reinforced composites portrayed an increasing pattern due to the increase of graphite particle loading into the polymer matrix. A fluctuate value at low loading of graphite was observed where $R$ and DPS are low. Eventually, as $R$ and DPS values increased, the matrix achieved mechanical percolation threshold on $\mathrm{WPUG}_{20}$ composites for both systems. It is about $440 \%$ of increment in the elastic modulus value where the initial WPU at 27 MPa leads to a dramatic improvement with the addition of graphite to a maximum of $146 \mathrm{MPa}$ for WPUG30 composites. Furthermore, the tensile strength also revealed an increment of about $100 \%$ of the matrix. As the graphite particles increase, the strength increases from 3.5 MPa up to maximum 6.5 $\mathrm{MPa}$. This can be assigned to the load distribution efficiently throughout the graphite particles and the matrix [39] as a result of the increment of carbonyl hydrogen index and phase separation of soft and hard segments. The inclusion of graphite particles led to strong intermolecular interactions between the waterborne polymer groups and the surface functional groups of the graphite, such as $-\mathrm{OH}$ and $-\mathrm{COOH}$, thereby increasing the critical energy release and fracture toughness values. Thus, this waterborne polyurethane-based graphite-reinforced composite obeys the rule of mixtures in which any increment in filler loading will increase the modulus of the polymer composite [40, 41].

Additionally, a similar pattern for elastic modulus has also been observed for nanographite platelets (NGPs) reinforced polylactide (PLA) [42]. However, as a result of addition of NGP contents in neat PLA, tensile strength of the system gradually decreased. This condition might be due to the presence of weak regions in the matrix-graphite system where loops in several chains are in close proximity but do not interconnect with one another. Cai et al. [37] proposed that the graphite and its constituent perform two roles in conjunction with the morphology of the polymer-based PU: (1) the chemical cross-linker for isocyanate-terminated PU and (2) the destroyer of the crystalline hard segment. These characteristics affect the mechanical properties of the PU in opposite ways. One can predict that the strength of the composites would increase up to a maximum point where it achieved the strength of the filler itself. Moreover, with the increment of graphite particles, waterborne polyurethane-based graphite-reinforced composites exhibit a classical brittle fracture, in which they do not reveal a notable yield phenomenon before its fracture.

In spite of that, the elongation at break or break displacement of waterborne polyurethane-based graphitereinforced composites present a declined order with increasing of graphite particles as indicated in Figure 6(c). It is about $\sim 50 \%$ decrement from origin to $\mathrm{WPUG}_{20}$ composites and another dropped of $\sim 50 \%$ at $\mathrm{WPUG}_{25}$ composites. The graphite particles create a discontinuity of waterborne polyurethane in polymer matrix in which they promote a stress concentration phenomenon and stiffening effect.

As the system at an unstrained state, the polymeric chains are highly coiled with random dispersion. Most of the soft segment comprised ether group where $\mathrm{C}-\mathrm{O}$ bond is easier to rotate and attributes to the molecular flexibility. However, as the waterborne polyurethane-based graphitereinforced composites underwent strain, the soft segment disentangled and straightened in conjunction with addition of graphite particles. Additional elongation diminishes the intrinsic cohesive energy, and structures of soft and hard segments reoriented normal to the applied stress. Furthermore, aromatic rings in the hard segment limit molecular flexibility due to crystallization and steric hindrance [35]. The waterborne polyurethane-based graphite-reinforced composites achieved its elongation limit on $\mathrm{WPUG}_{25}$ and WPUG $_{30}$ composites as the values approach uniformity. Previous research suggests that the modulus of the composites can be improved by adding fillers that have a high modulus to the polymer that has a lower modulus, without taking into account the interaction between them. However, such an outcome would require a complex explanation, which is beyond any complex theories, yet it can be simplified by putting the extrinsic filler as a restrictive effect over the polymeric materials by limiting the movement and deformation of its molecular chains [43].

3.3. Dynamic Mechanical Behavior. The viscoelastic properties of waterborne polyurethane and its composites under applied stress and elevated temperature were studied by dynamic mechanical analysis (DMA). Figure 7 represents the dynamic mechanical properties of waterborne polyurethane-based graphite-reinforced composites as a function of temperature. One can recognize that the addition of graphite particles results in substantially higher storage modulus $\left(E^{\prime}\right)$ and $\tan \delta$ values in the whole temperature range, compared to that of pure waterborne polyurethane. At a starting temperature of $30^{\circ} \mathrm{C}$, the magnitude of $E^{\prime}$ recorded for pure waterborne polyurethane is $22 \mathrm{MPa}$ and increases slowly with addition of graphite. However, a drastic increment of $360 \%$ to $80 \mathrm{MPa}$ was observed on $\mathrm{WPUG}_{20}$ composites and continues to improve to $118 \mathrm{MPa}$ on $\mathrm{PG}_{30}$ composites. Ironically, the values of the storage modulus are correlated with the elastic modulus in the previous section. This can be well explained by the immobilization of polymer chains due to graphite particles that act as the reinforcing filler; hence, the stiffness of the polymer matrix is interpreted.

It is noted here that the low-temperature zone corresponds to the glassy state of the polymer. Therefore, the storage modulus is very high at this region and decreases slowly with respect to increasing temperature as the polymer chain segments are frozen. As the temperature increases, free segments begin to move and the excess energy dissipates into heat. In a certain range of temperature (transition region), 


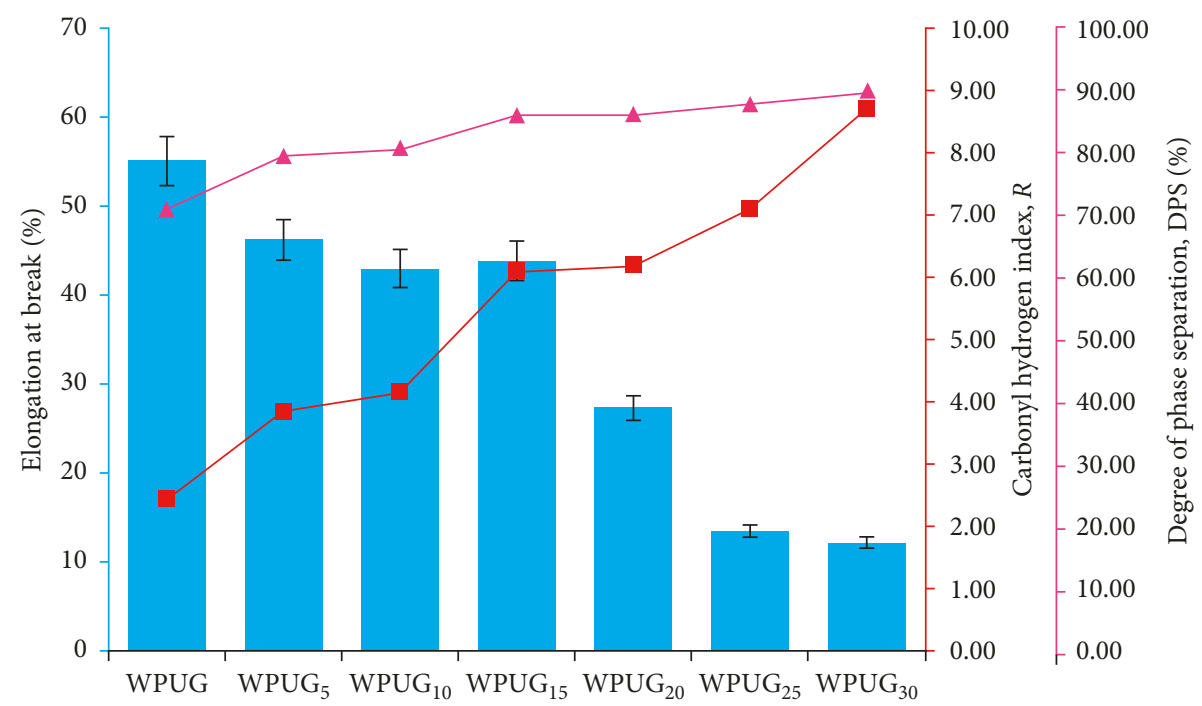

(a)

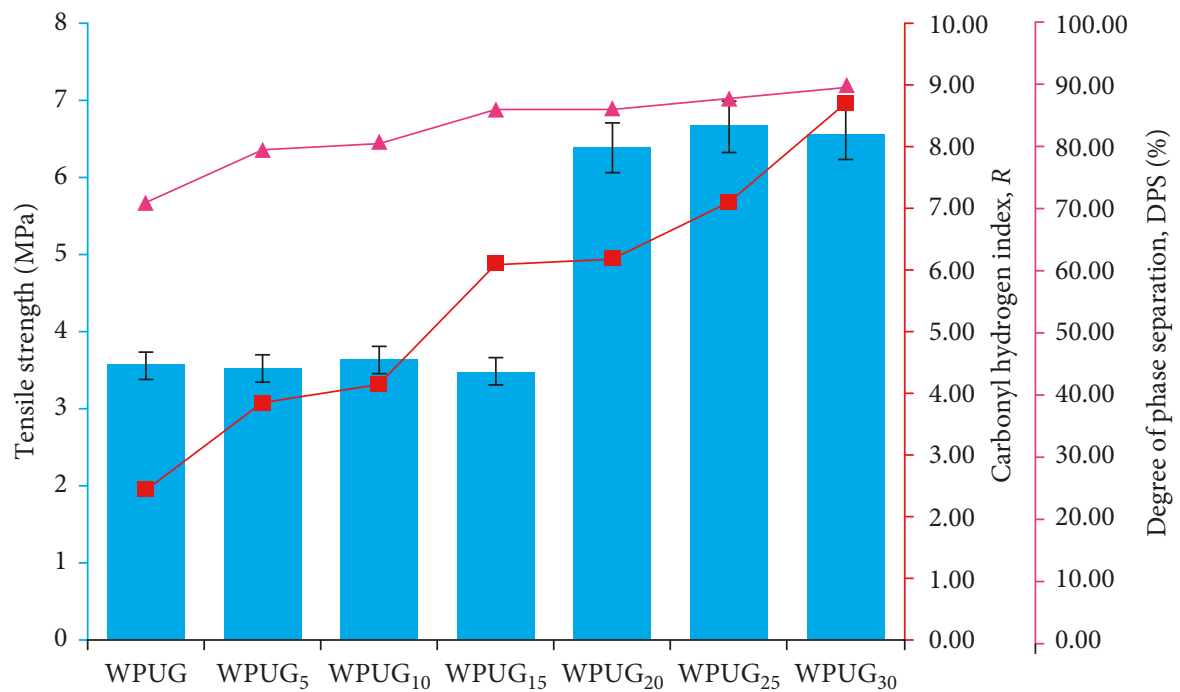

(b)

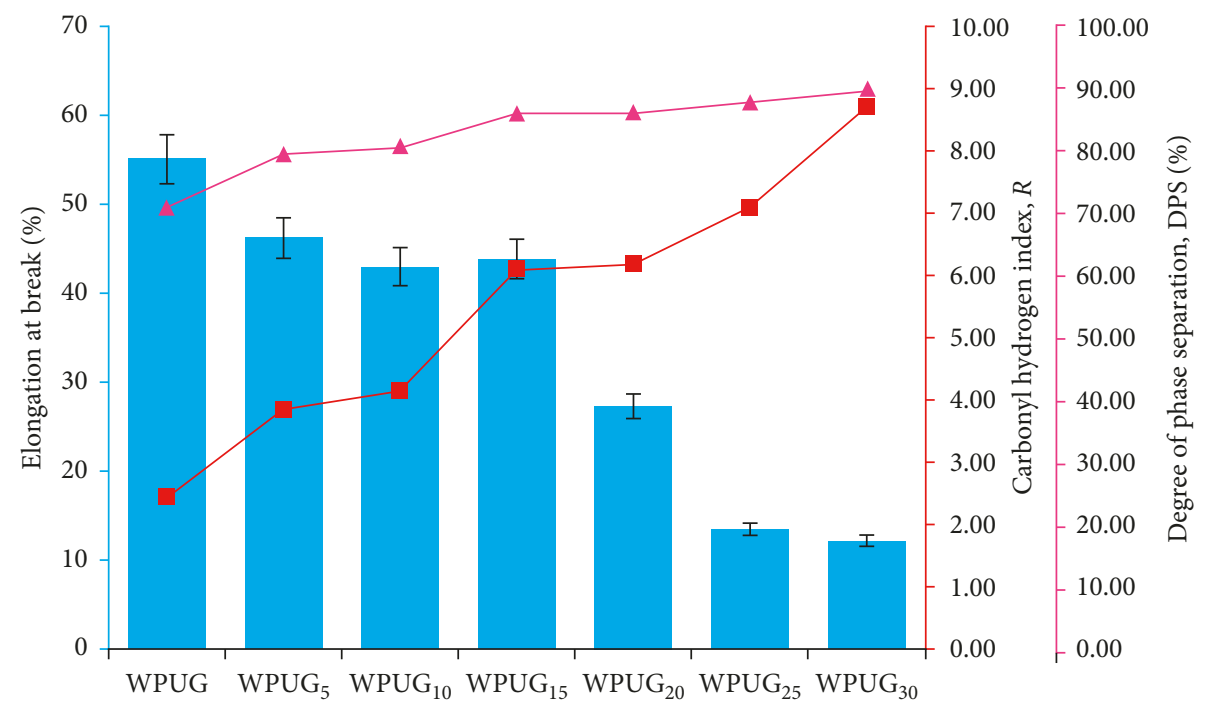

(c)

FIgURE 6: Tensile properties: (a) elastic modulus, (b) tensile strength, and (c) elongation at break (\%) of waterborne polyurethane-based graphite-reinforced composites in comparison with the degree of phase separation (DPS). 


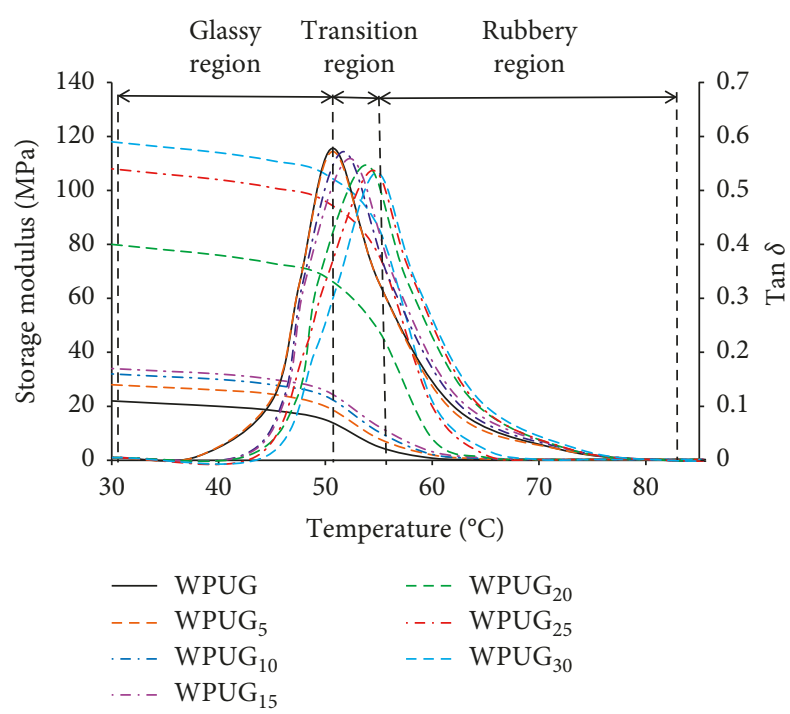

Figure 7: Dynamic mechanical properties of waterborne polyurethane-based graphite-reinforced composites; storage modulus, $E^{\prime}$, and $\tan \delta$, respectively.

the waterborne polyurethane chains reach their maximum, causing the mechanical strength to significantly and rapidly decrease, and this temperature range is called the glass transition $\left(T_{\mathrm{g}}\right)$ region. As the temperature goes higher than $T_{\mathrm{g}}$, the composite shows the viscoelasticity or rubbery properties due to free movement of the molecular chain; therefore, the storage modulus displays a very low rigidity and elasticity. The same pattern was also observed in the previous research [44-46]. The mechanical damping ability, which is measured by the height of $\tan \delta$ signal, shows a decreasing pattern by the increment in graphite particles. Despite that, the amplitude of each composite is still in the high range of $0.58-0.53$ whereby the temperature range with $\tan \delta>0.3$ is taken as a standard to evaluate damping materials [47].

The above results can be attributed to the fact that segmented waterborne polyurethane with flexible chains had greater friction force. When the load is transferred, friction between polymer chains increases so does the rate of dissipating energy. These cause the waterborne polyurethane with higher internal friction to have the better damping properties in comparison with its consequent composite. However, as the addition of graphite particles into the polymer increased, the matrix interface bonding results in immobility of the polymeric chain and hence restricts the mechanical damping. Thus, the reduction of the amplitude is observable. Furthermore, the $\tan \delta$ analysis also implies that the waterborne polymer is strongly bonded to graphite particles as it consists of high carbonyl hydrogen index which promote interconnected interface of the matrix as aforementioned. This mechanical damping result is identical with the experimental pattern in case of CNT-filled polyurethane composites [15], regardless of its values. Theoretically, the mechanical damping or internal friction $(\tan \delta)$ indicates the amount of energy dissipated as heat during the deformation [47-49]. From the industrial and structural point of view, the damping parameter is essential due to environmental impacts. This becomes a concern due to the application of a high damping material to a vibrating surface that converts the energy to heat which is distributed within the material itself and is not radiated as airborne noise. Thus, a specific damping or internal friction is required which refines the effect of undesirable vibrations to safer limits.

On the contrary, the $\tan \delta$ graph also shows shifted magnitude which corresponds to glass transition temperature, $T_{\mathrm{g}}$. $T_{\mathrm{g}}$ in polymer composites is particularly important due to the associated gains in thermal stability are critical for many applications and as well as they yield insights into fundamental changes in polymer chain dynamics. As been determined from the midpoints of the glass transition region of the damping curves, $T_{\mathrm{g}}$ values of waterborne polyurethane-based graphite-reinforced composites shifted slightly to higher temperature with the increase of the graphite particles, an unprecedented shift of nearly $2^{\circ} \mathrm{C}$ upon each composite. As recorded, the $T_{\mathrm{g}}$ values of the polymeric soft segment is in the range of $50.7-54.8^{\circ} \mathrm{C}$. It is said that the presence of carbon in the composites would inhibit the mobility of polymer which attributed to "tortuous path" effect. This effect delays the escape of volatile degradation products and char formation, whereby responsible for the improvement in thermal stability [50]. Ironically, previous work reported a decreasing value in glass transition temperature of the GO epoxy composites due to bad thermal stability of GO containing oxygen functional groups [51]. Moreover, the overloading nanosheets of GO can generate an irreversible aggregation, curled up and thicker, in some way jeopardising the $T_{g}$ of the composites. Therefore, this research suggests that graphite particles have the ability to promote thermal stability of the polymer matrix, which is consistent with the recent report [52].

3.4. Optical Studies. It is a significant method to attain optical constants such as absorption coefficient $(\alpha)$, extinction coefficient $(k)$, and optical energy band gap of materials through the optical absorption spectrum. The vital absorption is used to verify the character and value of the optical band gap which it corresponds to the electron excitation from the valence band to the conduction band. Currently, a carbon-based composite as a filler in the polymer matrix has been used to make a red shift to the absorbed light. UV-visible spectra of the prepared samples were performed in the $300-900 \mathrm{~nm}$ range as shown in Figure 8. The absorption features of waterborne polyurethane-based graphite-reinforced composite show absorption at range $300-400 \mathrm{~nm}$, and it corresponds to $n-\pi^{*}$ transition of $\mathrm{sp}^{2}$ which arises owing to the oxygen atoms of waterborne polyurethane groups and graphite carbon skeleton [53]. It is noticeable that there is an increase of absorbance upon the addition of graphite filler in waterborne polyurethane matrix of both low and high wavelengths wherein confirming the present of absorbing photoproducts (e.g., conjugated double bonds) in the composites [54]. The addition of graphite filler may also increase the polymeric concentration linearly. It is assumed that the microviscosity of the composites increases slowly. 


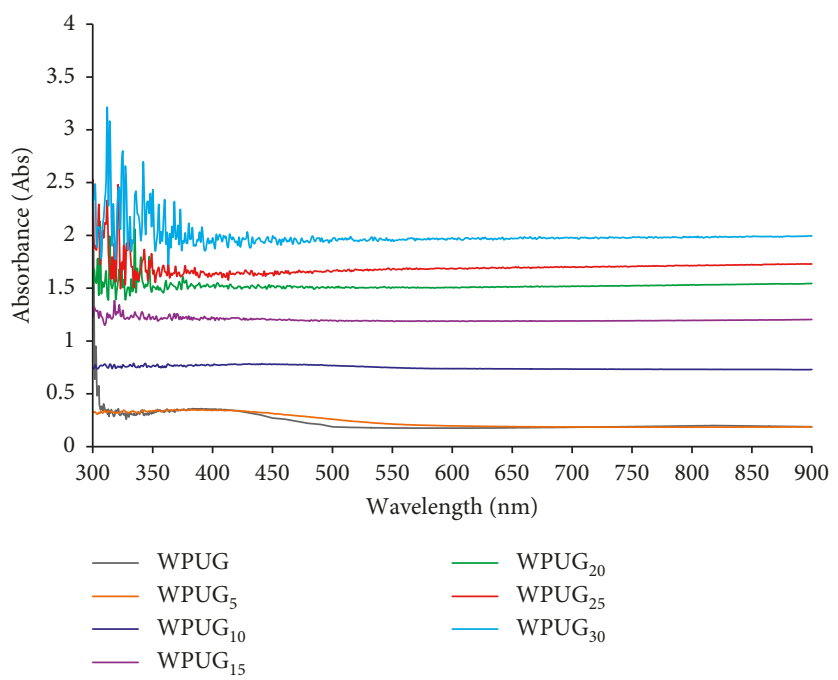

FIGURE 8: UV-Vis spectra of waterborne polyurethane-based graphite-reinforced composites.

From the optical data measurements, it can be concluded that the optical energy band gap of the waterborne polyurethane-based graphite-reinforced composites may be altered upon the addition of graphite particles. This can be more understood by calculating the optical energy band gap $\left(E_{\mathrm{g}}\right)$ of the waterborne polyurethane-based graphitereinforced composites using Tauc's relation. The values of the optical energy band gap of composite thin films were obtained and plotted as in Figure 9. Based on the graph, it was found that the optical energy band gap value is decreasing with increasing of graphite particles in the polymer matrix, from $4.10 \mathrm{eV}$ at $\mathrm{WPUG}_{0}$ to $3.98 \mathrm{eV}$ at $\mathrm{WPUG}_{30}$. One possible explanation of this study is that the graphite particles introduce multiple valence states in waterborne polyurethane structure and thus decrease the band gap energy between the valence and conductions bands.

\subsection{Electrical Resistivity and Conductivity Studies. Electrical} properties of waterborne polyurethane-based graphitereinforced composites generally depend on the rate of dispersion and structure of conducting graphite content along with the properties of host polymers. Theoretically, addition of conductive graphite to a classical insulating waterborne polyurethane can produce electrically conductive composite as the resistivity decreased $[52,55]$ if the extrinsic concentration exceeds the percolation threshold. Figure 10 shows I-V characterization and the variation of the electrical conductivity of waterborne polyurethane-based graphite-reinforced composites as a function of graphite content. The calculated value of electrical conductivities from the reciprocal of its resistivity increased significantly from $60-70 \times 10^{3} \mathrm{~S} / \mathrm{m}$ in $\mathrm{WPUG}_{20}, \mathrm{WPUG}_{25}$, and $\mathrm{WPUG}_{30}$ composites. This can be explainable as WPUG composites with higher graphite concentration, a larger number of conductive pathways are available.

At zero and low graphite content, low electron mobility in the composites were observed due to low magnitude (lower than $10^{\circ} \mathrm{S} / \mathrm{m}$ ) of conductivity in which the electrical characteristic cannot be justified by the IV test. A conduction path could not form as the system major filled by insulating waterborne polymer. This limitation can be related to the presence of functional groups of the waterborne polyurethane that can be oxidized or reduced causing increase in the background current. Contrary to higher graphite content, the internal insulating waterborne polyurethane gaps tend to become smaller with increasing graphite filler assuming that the graphite is uniformly dispersed in the polymer matrix. This leads to smaller resistivity values with increasing filler content, favoring the occurrence of conductivity. A critical point where the conduction path starts to trigger is called the percolation threshold. These percolation phenomena are observable at $\mathrm{WPUG}_{20}$ as the conductivity of the system can be calculated. The increment content of graphite results in a continuous conductive network with the better value of conductivity. At certain point, the conductivity of waterborne polyurethane-based graphite-reinforced composites constantly remains as the same regardless of the increasing content of graphite due to the initial properties of graphite. The expected conduction system by direct analytical measurements due to low currents implied is difficult to validate or invalidate. Consequently, it is suggested that different measurement techniques should be investigate, for example, surface conductivity, thermally stimulated DC current, DC conductivity, for better understanding the connection between their electrical properties [55].

\section{Conclusion}

In this research, the waterborne polyurethane by reactions of synthesized vegetable cooking oil, crosslink with methylene diphenyl diisocyanate (MDI) and reinforced with graphite particles have been successfully prepared through the casting method. The morphology-structure relation through FESEM and FTIR shows the random homogeneous distribution of graphite particles within the waterborne polymer matrix. It is also verified that the existence of soft and hard 


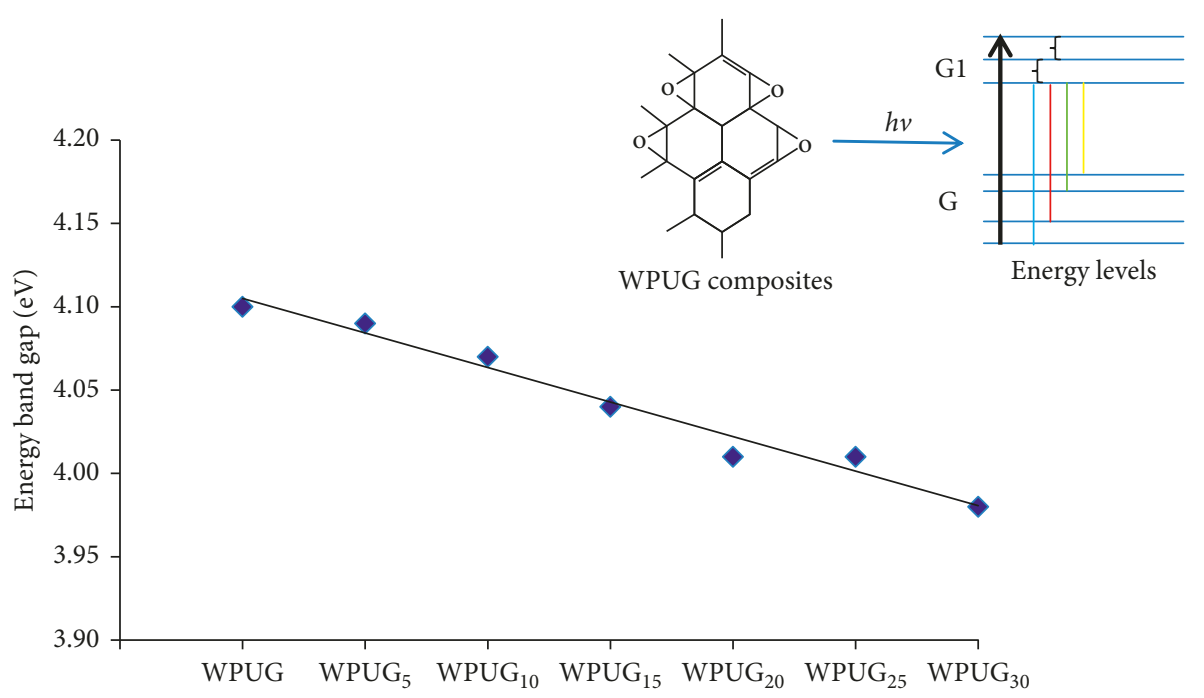

FiguRE 9: Optical energy band gap of waterborne polyurethane-based graphite-reinforced composites.

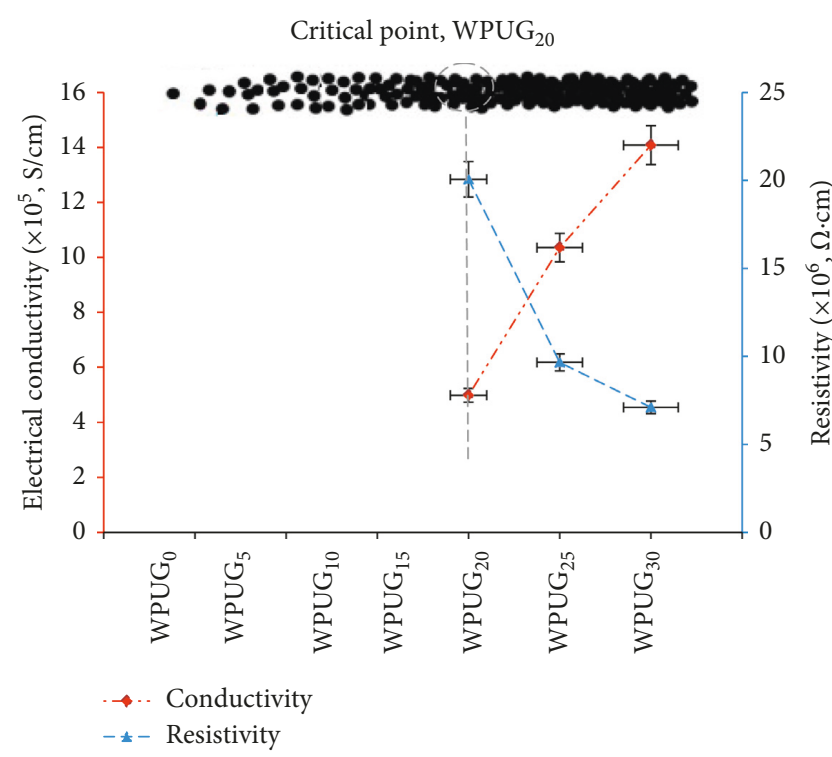

Figure 10: The resistivity and electrical conductivity $(\sigma)$ waterborne polyurethane-based graphite-reinforced composites.

segments in the system were affected with increasing of graphite and thereby provide better explanations for the mechanical, optical, and electrical properties. Moreover, both tensile strength and modulus of the composite films dramatically increased while the elongation at break decreased was observable as the amount of graphite particles loading increased and achieved mechanical percolation threshold at $\mathrm{WPUG}_{20}$. Despite that, higher crosslink density in this experiment through DMA results in lower polymer chain mobility and stronger material with higher $E^{\prime}$ and leads to an increase in $T_{g}$. The increment values at both $T_{g}-10^{\circ} \mathrm{C}$ and $T_{g}+10^{\circ} \mathrm{C}$ are with respect to graphite particle loading. In further case, the absorption spectrum shows absorption at range $300-400 \mathrm{~nm}$, and it corresponds optical energy band gap $\left(E_{\mathrm{g}}\right)$ using Tauc's relation were recorded at a range of 4.1 to $3.9(\mathrm{eV})$. The decreasing optical energy band gap with increasing graphite particles in the polymer matrix explained that the graphite particles introduce multiple valence states in waterborne polymer structure and thus decreasing the band gap energy between the valence and conductions bands. The internal insulating waterborne polyurethane gaps tend to become smaller with increasing graphite particles which leads to smaller resistivity values with increasing filler content, favoring the occurrence of electrical conductivity. A critical point where conduction path starts to trigger is called the percolation threshold, and these phenomena were observable at $\mathrm{WPUG}_{20}$ composites.

\section{Data Availability}

The data used to support the findings of this study are included within the article.

\section{Conflicts of Interest}

The authors declare that there are no conflicts of interest regarding this paper.

\section{Acknowledgments}

This research was supported in part by Fundamental Research Grant Scheme (Phase 1/2015) and Ministry of Education Malaysia, vot 1534, Johor, as well as through MyBrain15 (MyPhD) and Universiti Tun Hussein Onn Malaysia (UTHM).

\section{References}

[1] P. Anastas and N. Eghbali, "Green chemistry: principles and practice," Chemical Society Reviews, vol. 39, no. 1, pp. 301-312, 2010.

[2] Y. Hancock, "The 2010 nobel prize in physics-groundbreaking experiments on graphene," Journal of Physics D: Applied Physics, vol. 44, no. 47, article 473001, 2011.

[3] A. Király and F. Ronkay, "Temperature dependence of electrical properties in conductive polymer composites," Polymer Testing, vol. 43, pp. 154-162, 2015. 
[4] J. Lipták, J. S. Ček, I. Pilarčíková, and V. Bouda, "Electrical properties of polymer-carbon black composites prepared from solution," Nanocon, vol. 2010, pp. 10-15, 2010.

[5] R. Sattar, A. Kausar, and M. Siddiq, "Advances in thermoplastic polyurethane composites reinforced with carbon nanotubes and carbon nanofibers: a review," Journal of Plastic Film \& Sheeting, vol. 31, no. 2, pp. 186-224, 2014.

[6] L. W. Yang, X. S. Zhang, H. T. Liu, and M. Zu, "Thermal resistant, mechanical and electrical properties of a novel ultrahigh-content randomly-oriented CNTs reinforced SiC matrix composite-sheet," Composites Part B: Engineering, vol. 119, pp. 10-17, 2017.

[7] S. H. Park, P. T. Theilmann, P. M. Asbeck, and P. R. Bandaru, "Enhanced electromagnetic interference shielding through the use of functionalized carbon-nanotube-reactive polymer composites," IEEE Transactions on Nanotechnology, vol. 9, no. 4, pp. 464-469, 2010.

[8] A. Olad and H. Gharekhani, "Preparation and electrochemical investigation of the polyaniline/activated carbon nanocomposite for supercapacitor applications," Progress in Organic Coatings, vol. 81, pp. 19-26, 2015.

[9] C. Xia, S. Zhang, H. Ren et al., "Scalable fabrication of naturalfiber reinforced composites with electromagnetic interference shielding properties by incorporating powdered activated carbon," Materials, vol. 9, no. 1, pp. 1-9, 2016.

[10] G. Wu, X. Xu, X. He, and Y. Yan, "Preparation and characterization of graphene oxide-modified sapium sebiferum oil-based polyurethane composites with improved thermal and mechanical properties," Polymers, vol. 10, no. 2, p. 13, 2018.

[11] A. J. Marsden, D. G. Papageorgiou, C. Valles et al., "Electrical percolation in graphene-polymer composites," 2D Materials, vol. 5, article 032003, 2018.

[12] A. Chakraborty, A. Agresti, R. Pizzoferrato, F. D. Matteis, A. Orsini, and P. G. Medaglia, "Study of structural and optical properties of low temperature photo-activated $\mathrm{ZnO}-\mathrm{rGO}$ composite thin film," Materials Research Bulletin, vol. 91, pp. 227-231, 2017.

[13] K. Pielichowska, J. Bieda, and P. Szatkowski, "Polyurethane/ graphite nano-platelet composites for thermal energy storage," Renewable Energy, vol. 91, pp. 456-465, 2016.

[14] L. Cai, A. Al-Ostaz, X. Li et al., "Processing and mechanical properties investigation of epoxy-impregnated graphene paper," Journal of Nanomechanics and Micromechanics, vol. 6, no. 3, article 04016005, 2016.

[15] J. Sethi, "Carbon nanotubes filled polyurethane nanocomposites: a filler morphology and surfactant study," MS thesis, Tampere University of Technology, Tampere, Finland, 2014.

[16] M. Strankowski, D. Włodarczyk, A. Piszczyk, and J. Strankowska, "Thermal and mechanical properties of microporous polyurethanes modified with reduced graphene oxide," International Journal of Polymer Science, vol. 2016, Article ID 8070327, 8 pages, 2016.

[17] S. Uran, A. Alhani, and C. Silva, "Study of ultraviolet-visible light absorbance of exfoliated graphite forms," AIP Advances, vol. 7, no. 3, article $035323,2017$.

[18] I. Al-mosawi Ali, H. Al-maamori Mohammad, and H. Almayalee Khalidah, "Spectroscopic studies of polyester-carbon black composites," Research Journal of Material Sciences, vol. 1, no. 2, pp. 10-14, 2013.

[19] S. Zhou, L. Yu, X. Song, J. Chang, H. Zou, and M. Liang, "Preparation of highly thermally conducting polyamide 6/graphite composites via low-temperature in situ expansion," Journal of Applied Polymer Science, vol. 131, no. 1, 2014.

[20] M. Y. Zakaria, A. B. Sulong, J. Sahari, and H. Suherman, "Effect of the addition of milled carbon fiber as a secondary filler on the electrical conductivity of graphite/epoxy composites for electrical conductive material," Composites Part B: Engineering, vol. 83, pp. 75-80, 2015.

[21] P. J. Brigandi, Electrically conductive multiphase polymer blend carbon-based composites, Ph.D.thesis, John Wiley \& Sons, Hoboken, NJ, USA, 2017.

[22] H. Xu, Y. Li, N.-J. Huang et al., “Temperature-triggered sensitive resistance transition of graphene oxide wideribbons wrapped sponge for fire ultrafast detecting and early warning," Journal of Hazardous Materials, vol. 363, pp. 286-294, 2019.

[23] A. Z. M. Rus, N. M. Abdullah, M. F. L. Abdullah, and M. I. F. Idris, "Graphite/bio-based epoxy composites: the mechanical properties interface," Applied Mechanics and Materials, vol. 799-800, pp. 115-119, 2015.

[24] C.-F. Cao, G.-D. Zhang, L. Zhao et al., "Design of mechanically stable, electrically conductive and highly hydrophobic three-dimensional graphene nanoribbon composites by modulating the interconnected network on polymer foam skeleton," Composites Science and Technology, vol. 171, pp. 162-170, 2019.

[25] M. Strankowski, D. Włodarczyk, A. Piszczyk, and J. Strankowska, "Polyurethane nanocomposites containing reduced graphene oxide, FTIR, Raman, and XRD studies," Journal of Spectroscopy, vol. 2016, Article ID 7520741, 6 pages, 2016.

[26] N. M. Abdullah, A. Z. M. Rus, and M. F. L. Abdullah, "Synergistic influence of graphite on biopolymer composites properties," Jurnal Teknologi, vol. 77, no. 32, pp. 11-19, 2015.

[27] Q. Wu, L.-X. Gong, Y. Li et al., "Efficient flame detection and early warning sensors on combustible materials using hierarchical graphene oxide/silicone coatings," ACS Nano, vol. 12, no. 1, pp. 416-424, 2018.

[28] A. Z. M. Rus, "Polymers from renewable materials," Science Progress, vol. 93, no. 3, pp. 285-300, 2010.

[29] N. M. Abdullah, M. S. Kamarudin, A. Z. M. Rus, and M. F. L. Abdullah, "Preparation of conductive polymer graphite (PG) composites," IOP Conference Series: Materials Science and Engineering, vol. 226, article 12181, 2017.

[30] A. Z. M. Rus, N. M. Abdullah, and M. F. L. Abdullah, "Interconnected interface enhanced electrical properties of graphite in bio-based epoxy from insulating to conductor composites," Indian Journal of Science and Technology, vol. 8, no. 17, pp. 8-12, 2015.

[31] Y.-J. Wan, L.-C. Tang, L.-X. Gong et al., "Grafting of epoxy chains onto graphene oxide for epoxy composites with improved mechanical and thermal properties," Carbon, vol. 69, pp. 467-480, 2014.

[32] J. Zang, Y.-J. Wan, L. Zhao, and L.-C. Tang, "Fracture behaviors of TRGO-filled epoxy nanocomposites with different dispersion/interface levels," Macromolecular Materials and Engineering, vol. 300, no. 7, pp. 737-749, 2015.

[33] L.-X. Gong, Y.-B. Pei, Q.-Y. Han et al., "Polymer grafted reduced graphene oxide sheets for improving stress transfer in polymer composites," Composites Science and Technology, vol. 134, pp. 144-152, 2016.

[34] C. Flores-Hernández, A. Colín-Cruz, C. Velasco-Santos et al., "All green composites from fully renewable biopolymers: chitosan-starch reinforced with keratin from feathers," Polymers, vol. 6, no. 3, pp. 686-705, 2014. 
[35] A. S. Ahmad Hazmi, N. N. P. N. Pauzi, Z. A. Maurad et al., "Understanding intrinsic plasticizer in vegetable oil-based polyurethane elastomer as enhanced biomaterial," Journal of Thermal Analysis and Calorimetry, vol. 130, no. 2, pp. 919-933, 2017.

[36] K. Liu, B. He, L. Qian, and J. Li, "Conducting graphite/ cellulose composite film as a candidate for chemical vaporsensing material," Bioresources, vol. 9, no. 3, pp. 5279-5289, 2014.

[37] D. Cai, K. Yusoh, and M. Song, "The mechanical properties and morphology of a graphite oxide nanoplatelet/ polyurethane composite," Nanotechnology, vol. 20, no. 8, article 085712, 2009.

[38] J. Vega-baudrit, S. M. Carballo, L. De Adhesión, U. De Alicante, and C. Rica, "Thermoplastic polyurethanes-fumed silica composites: influence of $\mathrm{NCO} / \mathrm{OH}$ in the study of thermal and rheological properties and morphological characteristics," in Thermoplastic-Composite Materials, pp. 12-24, IntechOpen, London, UK, 2012.

[39] A. Z. M. Rus, N. Munirah Abdullah, and M. F. L. Abdullah, "Mechanical behavior of ultra violet (UV) curable renewable polymer/graphite (PG)," Indian Journal of Science and Technology, vol. 9, no. 48, pp. 1-4, 2016.

[40] J. Ervina, M. Mariatti, and S. Hamdan, "Effect of filler loading on the tensile properties of multi-walled carbon nanotube and graphene nanopowder filled epoxy composites," Procedia Chemistry, vol. 19, pp. 897-905, 2016.

[41] N. M. Abdullah and M. F. L. Abdullah, "Mechanical reinforcement of conductive graphite/biopolymer thin film composite," ARPN: Journal of Engineering and Applied Sciences, vol. 10, no. 20, pp. 9772-9775, 2015.

[42] E. Narimissa, R. K. Gupta, H. J. Choi, N. Kao, and M. Jollands, "Morphological, mechanical, and thermal characterization of biopolymer composites based on polylactide and nanographite platelets," Polymer Composites, vol. 33, no. 9, pp. 1505-1515, 2012.

[43] C.-L. Huang, C.-W. Lou, C.-F. Liu, C.-H. Huang, X.-M. Song, and J.-H. Lin, "Polypropylene/graphene and polypropylene/ carbon fiber conductive composites: mechanical, crystallization and electromagnetic properties," Applied Sciences, vol. 5, no. 4, pp. 1196-1210, 2015.

[44] M. Bastiurea, M. S. Rodeanu, D. Dima, M. Murarescu, and G. Andrei, "Thermal and mechanical properties of polyester composites with graphene oxide and graphite," Digest Journal of Nanomaterials and Biostructures, vol. 10, no. 2, pp. 521-533, 2015.

[45] V. Sridhar, I. Lee, H. H. Chun, and H. Park, "Graphene reinforced biodegradable poly (3-hydroxybutyrate-co-4hydroxybutyrate) nano-composites," Express Polymer Letters, vol. 7, no. 4, pp. 320-328, 2013.

[46] L.-C. Tang, Y.-J. Wan, D. Yan et al., "The effect of graphene dispersion on the mechanical properties of graphene/epoxy composites," Carbon, vol. 60, pp. 16-27, 2014.

[47] S. Chen, T. Wang, Q. Wang, and X. Pei, "Damping properties of polyurethane/epoxy graft interpenetrating polymer network composites filled with short carbon fiber and nano$\mathrm{SiO}_{2}$," Journal of Macromolecular Science, Part B, vol. 50, no. 5, pp. 931-941, 2011.

[48] N. N. M. Hassan, A. Z. M. Rus, S. Nurulsaidatulsyida, and S. R. Mohid, "Acoustic study based on sustainable green polymer treated with $\mathrm{H}_{2} \mathrm{O}$," Advanced Materials Research, vol. 748, pp. 281-285, 2013.

[49] A. Z. M. Rus and N. N. M. Hassan, "Thermal degradation and damping characteristic of UV irradiated biopolymer,"
International Journal of Polymer Science, vol. 2015, Article ID 615284, 11 pages, 2015.

[50] Y. Cao, J. Feng, and P. Wu, "Preparation of organically dispersible graphene nanosheet powders through a lyophilization method and their poly (lactic acid) composites," Carbon, vol. 48, no. 13, pp. 3834-3839, 2010.

[51] J. Tang, H. Zhou, Y. Liang, X. Shi, X. Yang, and J. Zhang, "Properties of graphene oxide/epoxy resin composites," Journal of Nanomaterials, vol. 2014, Article ID 696859, 5 pages, 2014.

[52] N. M. Abdullah, A. Z. M. Rus, and M. F. L. Abdullah, "Enhancement of graphite functionality in renewable polymer composite properties," International Journal of Engineering \& Technology, vol. 7, no. 3.14, pp. 215-220, 2018.

[53] A. Z. M. Rus, N. M. Abdullah, M. F. L. Abdullah, and M. I. F. Idris, "Graphite/bio-based epoxy composites: structural, optical and electrical properties," Applied Mechanics and Materials, vol. 799-800, pp. 153-157, 2015.

[54] N. M. Elsayed, O. F. Farag, M. H. Elghazaly, and D. A. Nasrallah, "Investigation of the effects of fullerene addition and plasma exposure on optical properties of polystyrene films," IOSR Journal of Applied Physics, vol. 7, no. 6, pp. 64-70, 2015.

[55] T. S. Bachari, "Electric properties of polyvinyl acetate (PVA)polyol and prepared sulfonated phenol-formaldehyde resin (SPF) bulk samples composite," Asian Journal of Applied Science and Engineering, vol. 3, no. 2, pp. 33-44, 2014. 


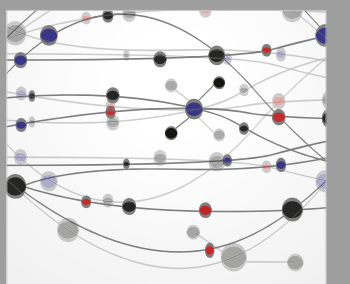

The Scientific World Journal
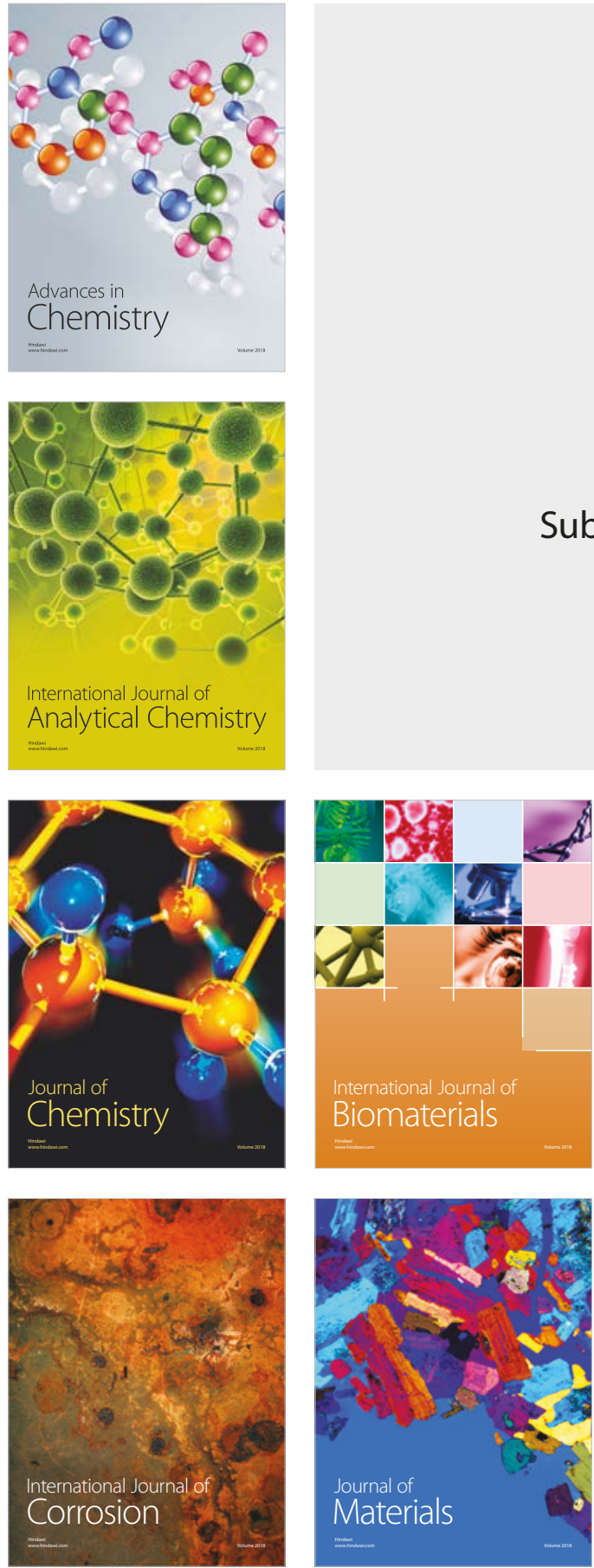

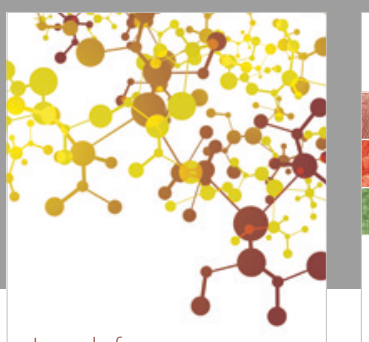

Journal of

Applied Chemistry
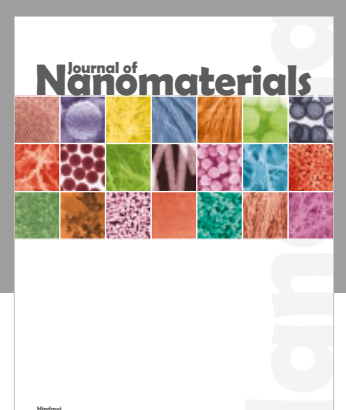

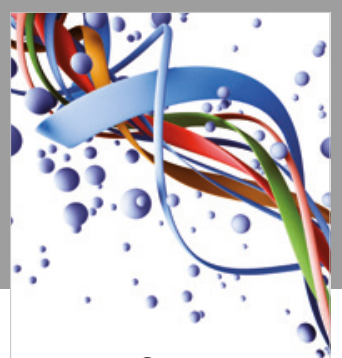

Scientifica

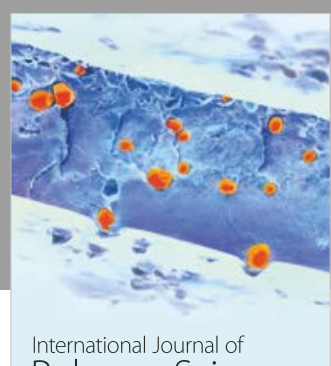

Polymer Science

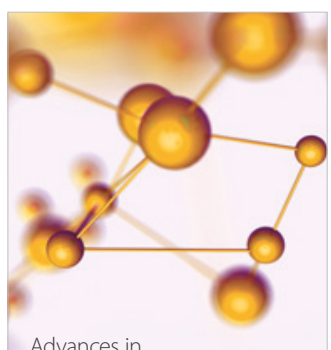

Physical Chemistry
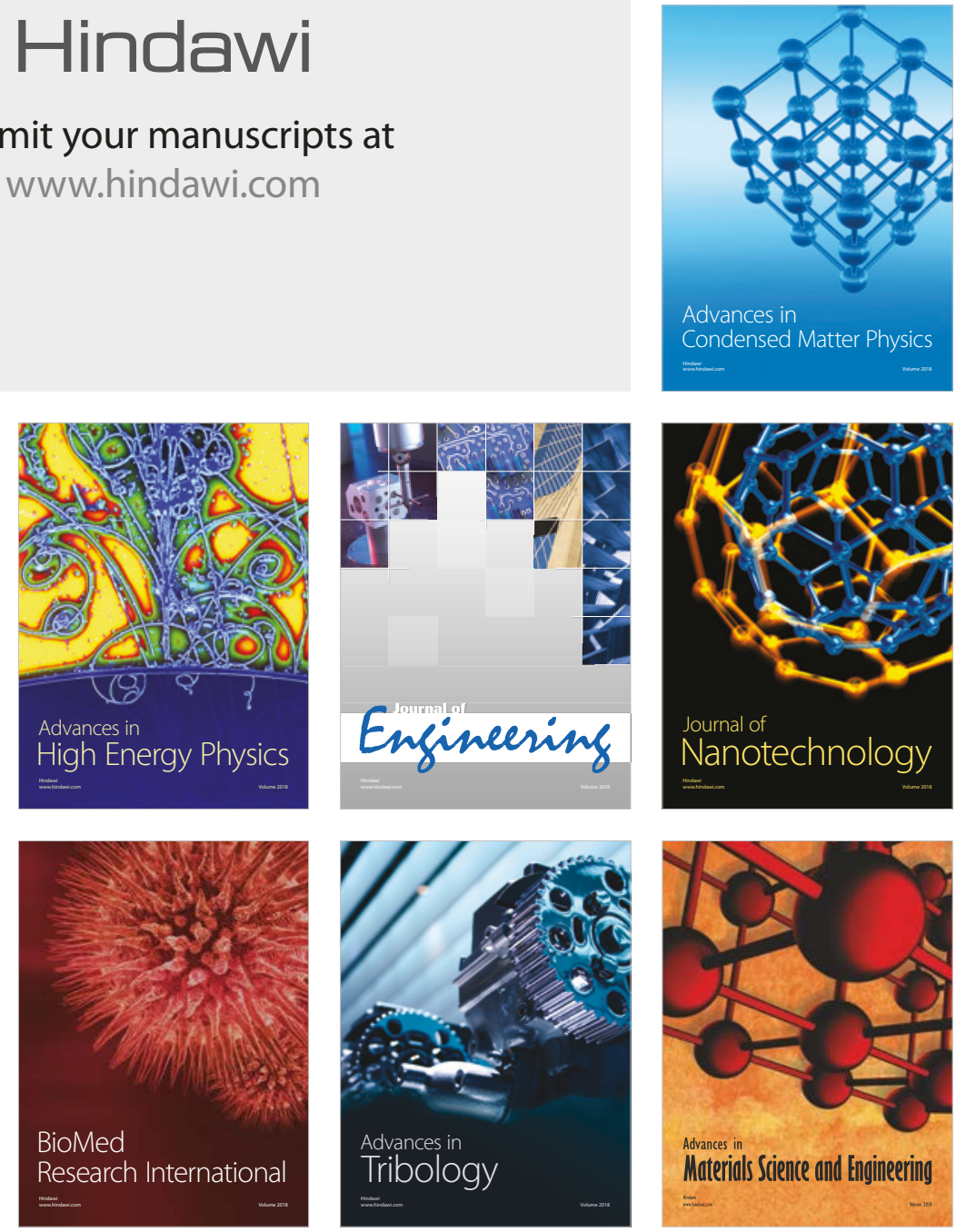